\title{
Enlarged lymph node or what else? A rare case of pulmonary artery aneurysm
}

\author{
Ersin GÜNAY ${ }^{1}$ \\ Furkan KAYA ${ }^{2}$ \\ Sibel GÜNAY ${ }^{3}$
}

1 Afyon Kocatepe Üniversitesi Tıp Fakültesi, Göğüs Hastalıkları Anabilim Dalı, Afyonkarahisar, Türkiye

${ }^{1}$ Department of Chest Diseases, Faculty of Medicine, Afyon Kocatepe University, Afyonkarahisar, Turkey

2 Afyon Kocatepe Üniversitesi Tıp Fakültesi, Radyoloji Anabilim Dalı, Afyonkarahisar, Türkiye

2 Department of Radiology, Faculty of Medicine, Afyon Kocatepe University, Afyonkarahisar, Turkey

${ }^{3}$ Afyonkarahisar Devlet Hastanesi, Göğüs Hastalıkları Kliniği, Afyonkarahisar, Türkiye

${ }^{3}$ Clinic of Chest Diseases, Afyonkarahisar State Hospital, Afyonkarahisar, Turkey
To the Editor,

A 45 year-old male without known chronical diseases presented to our chest diseases clinic with a complaint of productive cough for 2 weeks. On his physical examination, vital signs were in normal limits. Respiratory crackles were heard during inspiration on right lower lung zone. Other system examinations were normal. Laboratory test was also in normal limits. Posteroanterior (PA) chest X-Ray showed right hilar enlargement. Non-contrast enhanced computed tomography (CT) revealed a well marginated lesion that was located at the subcarinal region and pulmonary infiltration located on the posterior segment of the right lower lobe (Figure 1A). Antibiotics with amoxicillin clavulonate $1000 \mathrm{mg}$ bid and clarithromycin $500 \mathrm{mg}$ bid were prescribed for treatment of pneumonia. Fiberoptic bronchoscopy was performed for diagnosis of subcarinal lesion. Bronchoscopy revealed a pulsatile enlargement on main carina through the right main bronchus (Figure 1B). Convex probe endobronchial ultrasound (cp-EBUS) was also performed to visualize this pulsati- le lesion. EBUS revealed a distinct edged anechoic vascular lesion (Figure 1C). Color Doppler flow was verified the turbulent blood flow within this lesion (Figure 1D). Then, new contrasted computed tomography pulmonary angiography (CTPA) was employed to demonstrate this vascular anomaly with the differential diagnosis of pulmonary artery aneurysm (PAA). Right PAA located at the subcarinal region was exactly diagnosed and visualized after tomography images (Figure 2A-B). No additional comorbid situation associated with PAA was observed during echocardiography. Follow-up of patient was planned for PAA related complications (eg. hemoptysis, huge dilatation etc.).

\section{Yazıșma Adresi (Address for Correspondence)}

\section{Dr. Ersin GÜNAY}

Afyon Kocatepe Üniversitesi Tıp Fakültesi, Göğüs

Hastalıkları Anabilim Dalı,

AFYONKARAHISAR - TÜRKIYE

e-mail: ersingunay@gmail.com 

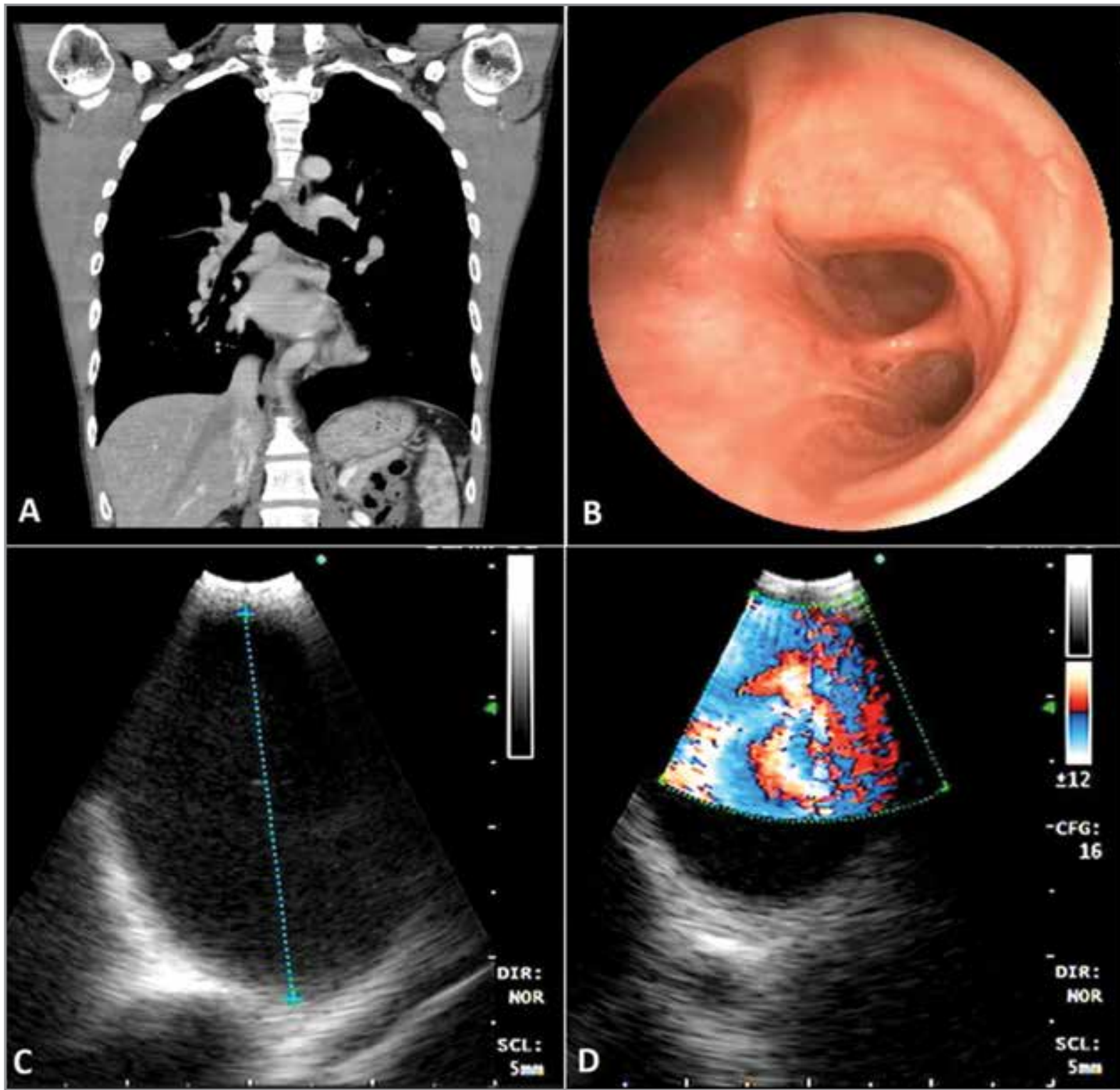

Figure 1. A. Computed tomography scan of the thorax showing subcarinal mass with right bronchial compression. B. Fiberoptic bronchoscopy revealed enlarged main carina and right bronchial compression with pulsation. C. B-mode convex probe endobronchial ultrasound (cp-EBUS) showed an anechoic distinct edged vascular image located at the subcarinal region. D. Turbulent blood flow was demonstrated by color Doppler flow during cp-EBUS.

Pulmonary artery aneurysms are uncommon and rarely misdiagnosed on non-or poorly contrast enhanced CT images $(1,2)$. Cp-EBUS and color doppler flow can be a useful technique to differentiate vascular lesions from lymph nodes and masses (2). Hence, cp-EBUS can help to avoid further investigations resulting in disastrous complications. 

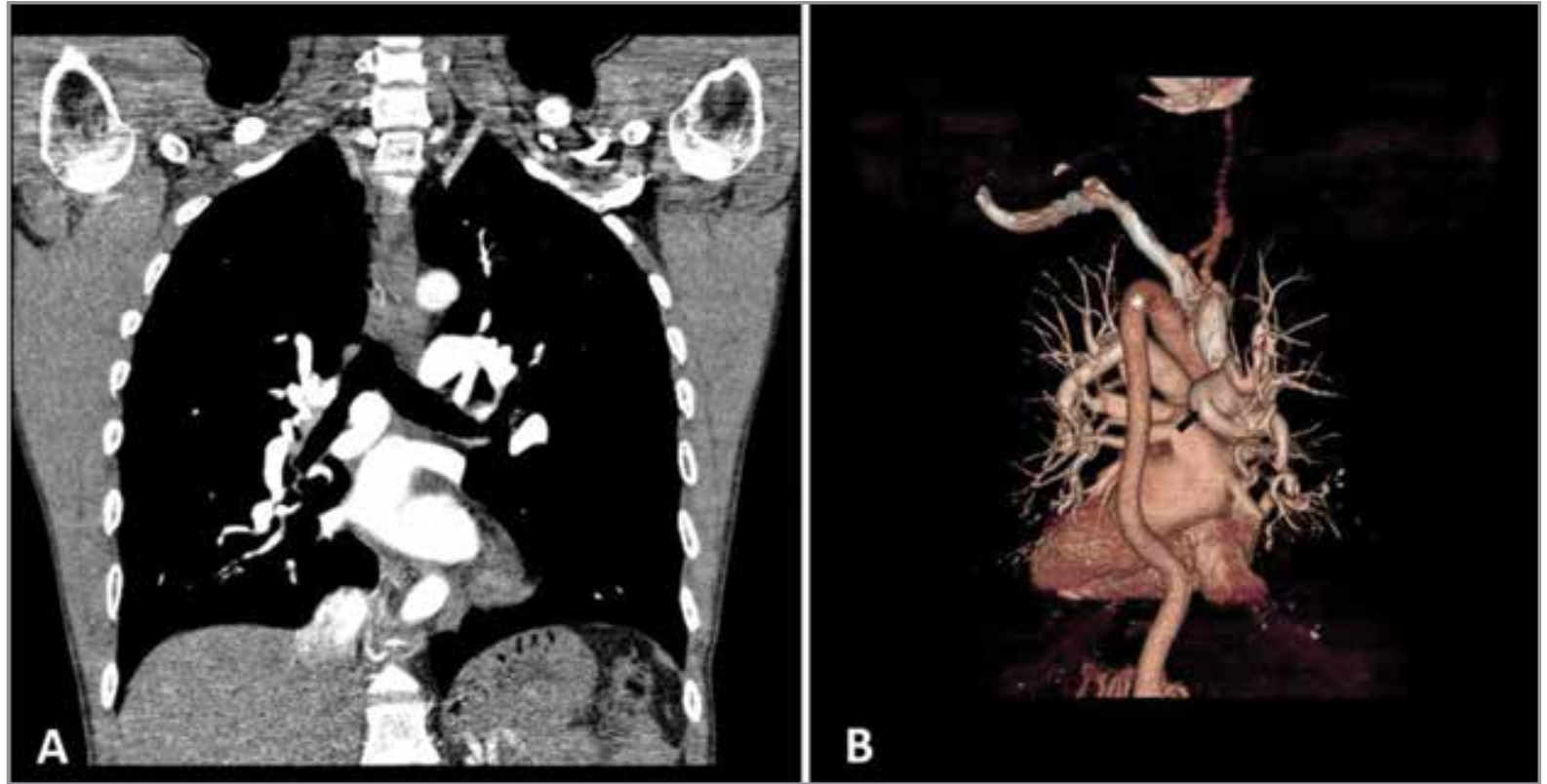

Figure 2. A. Computed tomography scan of the thorax and B. Three-dimensional reconstruction image revealed a pulmonary artery aneurysm of the right pulmonary artery. (Asterisk "*" showing arcus aorta, and black arrow showing right pulmonary artery aneurysm).

\section{REFERENCES}

1. Kreibich $M$, Siepe $M$, Kroll J, Höhn R, Grohmann J, Beyersdorf F. Aneurysms of the pulmonary artery. Circulation 2015;131:310-6.

2. Lerner $A D$, Riker DR. Use of endobronchial ultrasonography in the diagnosis of a pulmonary artery aneurysm. Ann Thorac Surg 2014;97:e139-41. 